\title{
ZCWPW1 is associated with late-onset Alzheimer's disease in Han Chinese: a replication study and meta-analyses
}

\author{
Yu Gao ${ }^{1, *}$, Meng-Shan Tan ${ }^{1, *}$, Hui-Fu Wang ${ }^{1}$, Wei Zhang ${ }^{2}$, Zi-Xuan Wang ${ }^{1}$, Teng \\ Jiang ${ }^{3}$, Jin-Tai $\mathbf{Y u}^{1}$, Lan Tan ${ }^{1}$ \\ ${ }^{1}$ Department of Neurology, Qingdao Municipal Hospital, School of Medicine, Qingdao University, Qingdao, PR China \\ ${ }^{2}$ Department of Emergency, Qingdao Municipal Hospital, School of Medicine, Qingdao University, Qingdao, PR China \\ ${ }^{3}$ Department of Neurology, Nanjing First Hospital, Nanjing Medical University, Nanjing, PR China \\ *These authors contributed equally to this work \\ Correspondence to: Lan Tan, e-mail: dr.tanlan@163.com \\ Jin-Tai Yu, e-mail: yu-jintai@163.com, Jintai.yu@ucsf.edu
}

Keywords: ZCWPW1, rs1476679, polymorphism, Alzheimer's disease

Received: November 21, 2015

Accepted: February 09, 2016

Published: March 06, 2016

\section{ABSTRACT}

Recently, a large genome-wide association study (GWAS) has identified a novel variant (rs1476679) within ZCWPW1 showing strong association with late-onset Alzheimer's disease (LOAD) in Caucasian. However, the effect of rs1476679 on other populations remains unclear. In order to explore whether rs 1476679 is also associated with the LOAD risk in other ethnic groups, we recruited 2350 unrelated Northern Han Chinese subjects, which include 992 LOAD patients and 1358 healthy controls. Analysis of data from these subjects suggests that the rs1476679 polymorphism is significantly associated with the LOAD (genotype $P=0.017$, allele $P=0.044$ ). The logistic regression reveals the $C$ allele at rs 1476679 is a protective factor for LOAD in the dominant model $(\mathrm{OR}=0.779,95 \% \mathrm{CI}=0.659-0.921, P C=0.009)$ adjusting for gender, age and $A P O E \varepsilon 4$ status. Furthermore, rs1476679 can decrease the AD risk (Dominant: $\mathrm{OR}=0.733,95 \% \mathrm{CI}=0.607-0.884, P c=0.006$; Additive: $\mathrm{OR}=0.820$, 95\%CI $=0.708-0.950, P C=0.048)$ in $A P O E \varepsilon 4$ non-carriers after stratification. Furthermore, meta-analysis of 82525 individuals confirmed that rs1476679 within ZCWPW1 decreased the risk of LOAD $(O R=0.91,95 \% C I=0.89-0.94)$. To summarize, the rs1476679 polymorphism in ZCWPW1 is associated with LOAD in Northern Han Chinese population.

\section{INTRODUCTION}

Alzheimer's disease (AD) is a genetically complex multifactorial neurodegenerative disorder and can be regarded as the most common type of dementia, defined by extensive neuronal and synapses loss, the formation of extracellular amyloid- $\beta(A \beta)$ plaques as well as the accumulation of intracellular neurofibrillary tangles (NFTs) in the brain [1]. Even though AD influences 13\% of the population older than 65 years and $43 \%$ older than 85 years, its underlying pathogenesis still remains unclear [2]. Previous studies identified that multiple rare mutations in the APP, PSEN1, and PSEN2 genes contributes to early-onset familial AD. However, only the $\varepsilon 4$ allele of the apolipoprotein $E(A P O E)$ gene increases the risk of late-onset $\mathrm{AD}$ (LOAD). Unfortunately, $A P O E$ only contributes to approximately $20 \%$ of LOAD risk, suggesting that numerous additional $\mathrm{AD}$ risk loci have not been identified so far. Previous GWAS identified some other genomic regions associated with $\mathrm{LOAD}$, including $C L U$, PICALM, CR1, BIN1, MS4A, CD2AP, CD33, EPHA1, ABCA7, TREM2, etc. [3-10].

Recently, a large-scale GWAS study of AD, which included 74,046 individuals, adopted a two stage design and carried out a meta-analysis. 11 new discovered loci were found in this meta-analysis, ZCWPWI (rs1476679) can be seen as a member of them and have functional relevance [11]. He et al. applied solution NMR spectroscopy and determination of the 3D structure of ZCWPW1 (encoding zinc finger, CW type with PWWP 
domain 1). $Z C W P W 1$ is a histone modification reader and is involved in epigenetic regulation [12]. ZCWPW1 serves as an eQTL (expression quantitative trait loci) for GATS, PILRB and TRIM4 and show indications for affecting binding of RFX3 and CTCF [13]. Besides, in a large LD block, candidate gene called $N Y A P 1$ in the $Z C W P W 1$ region may activate the PI3K signaling pathway in neurons and thus inhibit LOAD incidence $[11,14]$. ZNF3 lies at the same locus on chromosome7 as $Z C W P W 1$, interacts with BAG3 which is response for ubiquitin/proteasomal functions in protein degradation and binding of BACH1 whose target genes have roles in the oxidative stress response and control of the cell cycle [15]. Studies summarized above suggest that there has a specifically association between NFTs and $Z C W P W 1$ in LOAD.

However, note that this GWAS study was conduct only in Caucasian populations [11], and the effects of rs 1476679 on other populations are yet unknown. Since variants and their frequencies of $Z C W P W 1$ in various ethnic groups might be different, replication is necessary to confirm the potential effects of $Z C W P W 1$ on other groups. In this study, we firstly conducted the genetic association study on rs 1476679 within ZCWPWI in Han Chinese.

\section{RESULTS}

We analyzed data from 2350 ethnic Northern Han Chinese subjects, which include 992 subjects (42\%) with probable LOAD and 1358 healthy control subjects (58\%) matched for age (age at onset for patients with LOAD compared with age at examination for control subjects; $P=0.067)$ and gender $(P=0.189)$. The demographic and clinical characteristics of AD and control subjects are summarized in Table 1. As expected, the scores of the Mini-Mental State Examination had significantly lower values for patients with LOAD $(11.94 \pm 6.21)$ than those for the control subjects $(28.49 \pm 1.09 ; P<0.001)$. The possession of at least one $A P O E \& 4$ allele was confirmed to increase the risk of developing LOAD $(\mathrm{OR}=2.451,95 \% \mathrm{CI}$ $=1.995-3.011, P<0.001)$. Then we examined the underlying association of the rs 1476679 polymorphism with the LOAD susceptibility.

Genotype distributions of the rs1476679 in ZCWPW1 gene in controls exhibited the Hardy-Weinberg equilibrium $(P>0.05)$. Based on the minor allele $(\mathrm{C})$ frequency in controls, our sample size had more than $95 \%$ power to detect the OR of 0.78 for LOAD between carriers and no-carriers, at a significance level (alpha) of 0.05 . The allele and genotype distributions of rs1476679 AD patients and control subjects are shown in Table 2. The frequency of the minor allele $\mathrm{C}$ was lower in LOAD compared to the controls $(28.9 \%$ vs. $31.7 \%)$. And there is significant difference between the LOAD patients and controls
$(\mathrm{OR}=0.879,95 \% \mathrm{CI}=0.774-0.977, P=0.044)$. Similarly, the genotypes of the LOAD patients were significantly different from those of the controls $(P=0.017)$. As showed in Table 3, rs1476679 strongly decreased the risk of LOAD in multivariate analysis under a dominant model $(\mathrm{OR}=0.779,95 \% \mathrm{CI}=0.659-0.921, P=0.003$, $P \mathrm{c}=0.009$ ) in total sample (adjusting for gender, age and $A P O E \& 4$ status).

Furthermore, to test the influence of the interaction between rs 1476679 and $A P O E \& 4$ genotype on the risk of developing LOAD, we analyzed them in logistic regression models. No interaction between rs1476679 and $A P O E \& 4$ status was observed after Bonferroni adjustment. To further investigate whether the presence of the APOE $\varepsilon 4$ allele significantly modified the association of rs 1476679 with LOAD, these data were stratified based on the presence/absence of the $A P O E \& 4$. The genotype and allele distributions in rs 1476679 between LOAD patients and controls are significantly different (genotype $P=0.004$, allele $P=0.010$ ) from subjects without $A P O E \& 4$ allele. In the subjects with $A P O E \& 4$ allele, the genotypic distributions $(P=0.049)$ have differences between LOAD and controls. However, no significant differences were observed in the allelic distributions $(P=0.385)$ between these two groups (Table 2). Multivariate analysis also reveals that significant differences only exist in APOE \&4 allele noncarriers (adjusting for only gender and age) (Dominant: $\mathrm{OR}=0.733,95 \% \mathrm{CI}=0.607-0.884$, $P c=0.006$; Additive: $\mathrm{OR}=0.820,95 \% \mathrm{CI}=0.708-0.950$, $\left.P_{c}=0.048\right)$. Analysis using the recessive models indicate that rs476679 has no effect on the development of LOAD neither in $A P O E \& 4$ allele noncarriers $(P=0.764)$ nor in $A P O E \& 4$ allele carriers after a Bonferroni adjustment $(P c=0.138)$.

We conducted a meta-analysis on the association of rs 1476679 and LOAD in a sample of 82525 individuals, and found rs1476679 showed significant association with LOAD $(\mathrm{OR}=0.91,95 \% \mathrm{CI}=0.89-0.94)($ Figure 1$)$ without evident analysis heterogeneity $\left(I^{2}=20.4 \%\right)$, and the statistical significance of the factors with a low heterogeneity was essentially unchanged from our current study and previous report.

\section{DISCUSSION}

Using a large sample of 922 LOAD patients and 1358 controls, we identified a significant association between the rs1476679 polymorphism and LOAD in a Northern Han Chinese population. Logistic regression analysis reveals that rs1476679 is associated with a decreased risk of LOAD in total sample. We found, after stratifying the subjects by $A P O E \& 4$ status, that this association exists only among $A P O E \& 4$ non-carriers, indicating that rs1476679 is associated with LOAD and can be regarded as an independent protect factor of the AD risk. 
Table 1: The characteristics of the study population

\begin{tabular}{|c|c|c|c|c|}
\hline & $\operatorname{AD}(n=992)$ & Control $(n=1358)$ & $P$ value & OR $(95 \% C I)$ \\
\hline Age at examination, years; mean $\pm \mathrm{SD}$ & $79.83 \pm 6.69$ & $75.49 \pm 6.48$ & $0.189 *$ & \\
\hline Age at onset, years; mean \pm SD & $75.17 \pm 6.08$ & & & \\
\hline Gender, $n(\%)$ & & & 0.067 & \\
\hline Male & $408(41.1)$ & $610(44.9)$ & & \\
\hline Female & $584(58.9)$ & $748(55.1)$ & & \\
\hline MMSE score, mean \pm SD & $11.94 \pm 6.21$ & $28.49 \pm 1.09$ & $<0.001$ & \\
\hline$A P O E \& 4$ status, $n(\%)$ & & & $<0.001$ & \\
\hline$A P O E \varepsilon 4(+)$ & $284(28.6)$ & $191(14.1)$ & & $2.451(1.995-3.011)$ \\
\hline$A P O E \& 4(-)$ & $708(71.4)$ & $1167(85.9)$ & & \\
\hline
\end{tabular}

Abbreviation: AD, Alzheimer's disease; Control, healthy controls; OR, odds ratio; CI, confidence interval; MMSE, MiniMental State Examination; $A P O E$, apolipoprotein E; SD, standard deviation.

$* P$ value was calculated with the age of onset for late-onset $\mathrm{AD}$ and age at examination for Control. Differences in the characteristics of age and MMSE score between the two groups were examined using Student's $t$ test. Differences in gender and $A P O E \& 4$ frequency between $\mathrm{AD}$ patients and Control were assessed using the Pearson $\chi 2$ test.

Table 2: Distribution of the rs1476679 alleles and genotypes in the AD cases and the controls

\begin{tabular}{|c|c|c|c|c|c|c|c|c|}
\hline & \multirow[t]{2}{*}{$\mathbf{N}$} & \multicolumn{4}{|c|}{ Genotypes $n(\%)$} & \multicolumn{3}{|c|}{ Alleles $n(\%)$} \\
\hline & & $\mathbf{C C}$ & CT & TT & $\mathbf{P}$ & $\mathrm{C}$ & $\mathbf{T}$ & $\mathbf{P}$ \\
\hline \multicolumn{9}{|c|}{$r s 1476679$} \\
\hline $\mathrm{AD}$ & 992 & $82(8.3)$ & $410(41.3)$ & $500(50.4)$ & 0.017 & $574(28.9)$ & $1410(71.1)$ & 0.044 \\
\hline Controls & 1358 & $110(8.1)$ & $640(47.1)$ & $608(44.8)$ & & $860(31.7)$ & $1856(68.3)$ & \\
\hline \multicolumn{9}{|c|}{$A P O E \& 4(+)$} \\
\hline $\mathrm{AD}$ & 284 & $20(7.0)$ & $134(47.2)$ & $130(45.8)$ & 0.049 & $174(30.6)$ & $394(69.4)$ & 0.385 \\
\hline Controls & 191 & $4(2.1)$ & $99(51.8)$ & $88(46.1)$ & & $107(28.0)$ & $275(72.0)$ & \\
\hline \multicolumn{9}{|c|}{$A P O E \& 4(-)$} \\
\hline $\mathrm{AD}$ & 708 & $62(8.8)$ & $276(39.0)$ & $370(52.3)$ & 0.004 & $400(28.3)$ & $1016(71.75)$ & 0.010 \\
\hline Controls & 1167 & $106(9.1)$ & $541(46.4)$ & $520(44.6)$ & & $753(32.3)$ & $1581(67.7)$ & \\
\hline
\end{tabular}

The recent large-scale GWAS identified their result $(\mathrm{OR}=0.91,95 \% \mathrm{CI}=0.89-0.94)$ that rs 1476679 decreased the risk of AD in Caucasian [11]. A following study using a large Spanish sample confirmed the same conclusion through multiple test $(\mathrm{OR}=0.846,95 \% \mathrm{CI}=0.769-0.932)$ [16]. However, a set of 1210 samples in Chinese Han and another study of 229 LOAD cases and 318 controls from mainland China found no significant association between rs 1476679 and AD [17, 18]. Here, our study identified rs 1476679 as a protective factor for LOAD risk. The discrepancy by no means invalidated the initial association and several reasons might attribute to them. The different sample sizes and possibility of false positives could account for this phenomenon. Besides, the complexity of clinical progression, as well as many unknown demographic and clinical variables, such as other medical illnesses and sources of disability, might also cause the bias of results [19]. Furthermore, the effects of some genetic variants confirmed by GWAS, might be population-specific, due to some unknown gene-gene or gene-environment interactions [20]. To avoid these possibly complicated reasons and further investigate these associations, metaanalysis was performed. The results showed that rs1476679 within $Z C W P W 1$ had a strong association with LOAD.

Regarding to the mechanisms by which the SNP in $Z C W P W 1$ result to LOAD, rs1476679 may be in LD with functional SNPs in ZCWPW1 gene. $Z C W P W 1$ contains the zinc finger $\mathrm{CW}$ (zf-CW) domain and the PWWP domain, shows functions in giving rise to chromatin remodeling and methylation states, as well as epigenetic regulations, respectively, indicating $Z C W P W 1$ as a histone modification reader $[12,21]$. As stated by Samantha et al., ZCWPW1 serves as an eQTL (expression quantitative trait loci) for GATS, PILRB and TRIM4 and affects binding of CTCF and RFX3, a variant in ZCWPW1 (rs1476679) associated with LOAD risk was considered to have functional relevance [21]. In addition, by activating binding of RFX3, an interesting transcription factor to act on glucokinase gene, we may hypothesis $Z C W P W 1$ decreases risk of LOAD through suppressing insulin resistance [13]. 
Table 3: Logistic regression analysis of rs1476679 polymorphisms

\begin{tabular}{|c|c|c|c|c|c|c|c|c|c|c|c|}
\hline \multirow[b]{2}{*}{ SNP } & \multicolumn{5}{|l|}{ Total sample ${ }^{\mathrm{a}}$} & \multicolumn{3}{|l|}{ APOE $\varepsilon 4(+)^{b}$} & \multicolumn{3}{|l|}{$A P O E \& 4(-)^{\mathrm{b}}$} \\
\hline & OR $(95 \% \mathrm{CI})$ & $P$ & $P c$ & $\begin{array}{l}P \text { for APOE } \\
\text { interaction }\end{array}$ & $P c$ & OR $(95 \% \mathrm{CI})$ & $P$ & $P c$ & OR $(95 \% \mathrm{CI})$ & $P$ & $P c$ \\
\hline \multicolumn{12}{|l|}{ rs1476679 } \\
\hline Dominant & $0.779(0.659-0.921)$ & $0.003 *$ & $0.009^{*}$ & 0.143 & & $1.003(0.692-1.453)$ & 0.987 & & $0.733(0.607-0.884)$ & $0.001 *$ & $0.006^{*}$ \\
\hline Additive & $0.871(0.763-0.995)$ & $0.041 *$ & 0.123 & 0.055 & & $1.159(0.845-1.592)$ & 0.360 & & $0.820(0.708-0.950)$ & $0.008^{*}$ & $0.048^{*}$ \\
\hline Recessive & $1.098(0.811-1.486)$ & 0.547 & & $0.024 *$ & 0.072 & $3.531(1.185-10.519)$ & $0.023 *$ & 0.138 & $0.951(0.684-1.321)$ & 0.764 & \\
\hline
\end{tabular}

Abbreviation: $P c$, the corrected $P$ value multiplied by 3 (the number of genetic models) in the total sample and by 6 in the $A P O E \varepsilon 4$ allele carrier and noncarrier subgroups as a Bonferroni adjustment.

$P C$ was only calculated when the $P$ value was less than 0.05 .

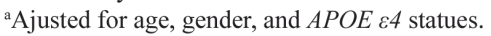

${ }^{\mathrm{b}}$ Ajusted for age and gender.

$* P<0.05$, significant values

The region of ZCWPW1 defined by SNPs associated with LOAD is part of a larger LD block, encompassing many candidate genes [22]. Another possible candidate gene in the $Z C W P W 1$ region is $N Y A P 1$, which disruption affects brain size, inhibits neurite elongation and, neuronal morphogenesis [11]. NYAP1 has role in the regulation of the PI3K signaling pathway in neurons, means it associates with $\mathrm{AD}$ risk mainly in this pathway [14]. In addition, ZNF3 lies at the same locus on chromosome 7 as $Z C W P W 1$, thereby it can be regarded as a candidate gene that contains the functional signal in this region [15]. ZNF3 may interact with BAG3 (involved in ubiquitin/ proteasomal functions in protein degradation) and binding of BACH1 (acting on the oxidative stress response and regulating the cell cycle), which are involved in tau pathology of AD. NYAP1 and ZNF3 might participate in

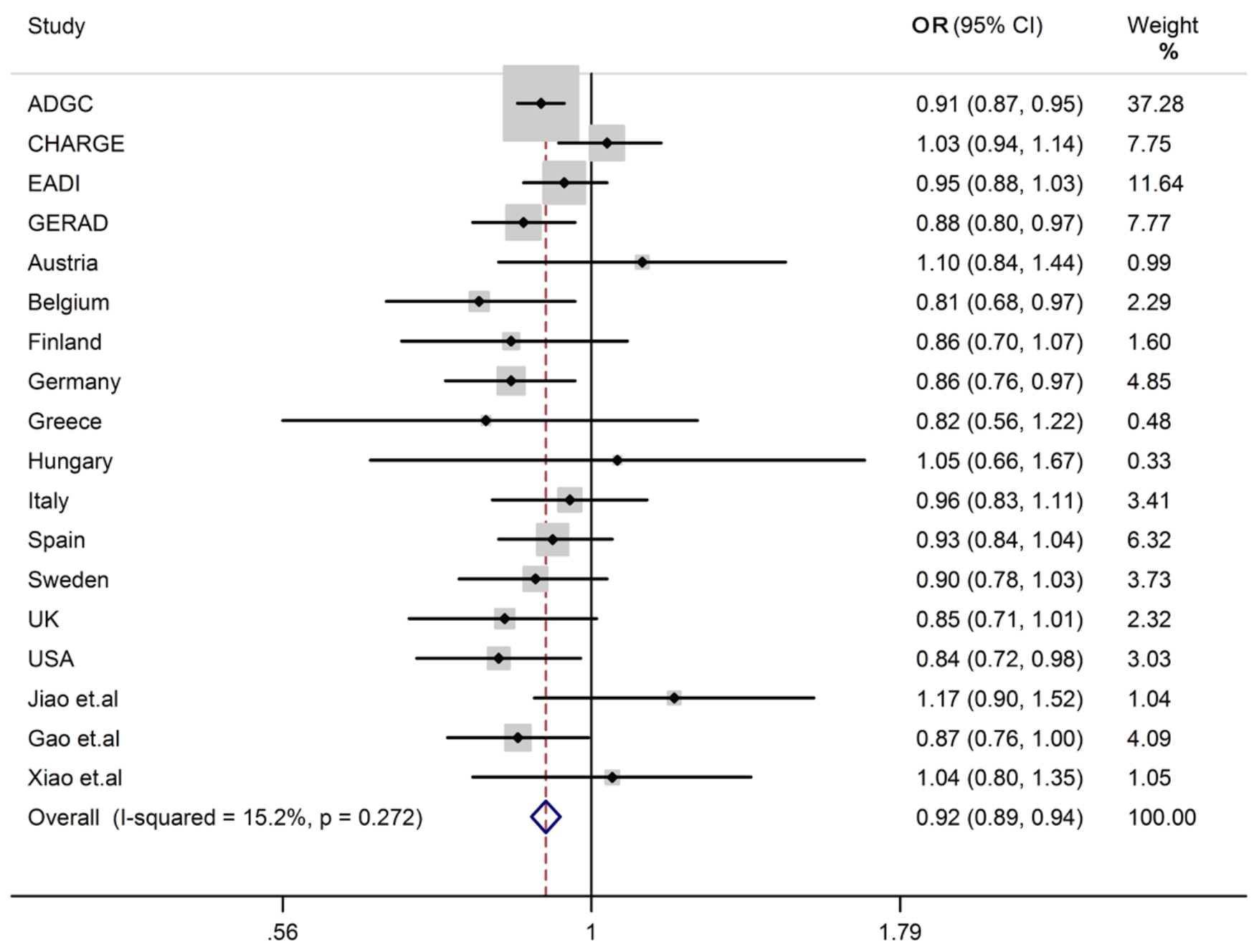

Figure 1: Forest plots for rs1476679 in LOAD and healthy controls in 82525 individuals. 
mechanisms of AD through the above pathways, although no studies reported the association between $N Y A P 1$ or ZNF3 gene and AD risk [23].

In conclusion, our study provided the first evidence that the carriage of $\mathrm{C}$ allele on the ZCWPWI (rs 1476679) was significant associated with LOAD in a North Han Chinese population. In consistent with the role of ZCWPW1 (rs1476679) in Caucasians, ZCWPW1 (rs1476679) also acted as a protective factor to the development of AD in Han Chinese. Further functional examinations into this locus and the region surrounding $Z C W P W 1$ are required to better elucidate the role of them and their interaction with $Z C W P W 1$ in AD pathogenesis. Besides, studies in more large cohorts and in other ethnic groups are needed to clarify the role of the locus at $Z C W P W 1$ in LOAD since genetic variations vary among the populations of different ethnic and geographical origin.

\section{MATERIALS AND METHODS}

\section{Subjects}

Our study investigated 2350 subjects comprising 992 sporadic LOAD patients (mean age at onset: $75.17 \pm 6.08$ years) and 1358 healthy controls subjects (mean age at examination: $75.49 \pm 6.48$ years) matched for age and gender. All the LOAD patients and control subjects are unrelated northern Han Chinese residents originally from Shandong Province, which is located in the North of China. The AD patients were recruited from the Department of Neurology at Qingdao Municipal Hospital, and several other 3A-level hospitals in Shandong Province. All patients were subjected to neuropsychological examination, structural neuroimaging consisting of brain computed tomography and/or magnetic resonance imaging. A consensus clinical diagnosis of probable AD was carried out by at least two neurologists according to the criteria of the National Institute of Neurological and Communicative Disorders and Stroke/ Alzheimer $s$ Disease and Related Disorders Association (NINCDS/ADRDA) [24]. All the patients are considered to be sporadic because none of their first-degree relatives have dementia in their family history. The information of patients, including age at onset and family history, were determined by their guardians. The age-and gendermatched healthy controls were recruited from the Health Examination Center of the Qingdao Municipal Hospital according to the principles described [25] and were confirmed healthy and neurologically normal by medical history, general examination, laboratory examination, and Mini Mental State Examination (score $\geq 28$ points) by physicians and neurologists. Demographic details of the sample set are shown in Table 1. Informed consent was obtained from all subjects or their caregivers, and the protocol of our study was approved by the Institutional Ethics Committees [20].

\section{Genotyping}

Genomic DNA was extracted from the peripheral blood leukocytes of AD patients and healthy individuals using the Wizard genomic DNA purification kit (Cat. \#A1125, Promega, USA). Genotyping of ZCWPW1 (rs1476679) and $A P O E$ (rs429358 and rs7412) polymorphisms were accomplished by the improved multiplex ligase detection reaction (iMLDR) method, with technical support from the Shanghai Genesky Biotechnology Company (genotyping details are available from the corresponding author) [2]. Data analysis was achieved using GeneMapper Software v4.1 (Applied Biosystems). These DNA samples, which were selected randomly from patients and controls, were sequenced to validate the genotyping using the ligation detection reaction method. Genotyping details are available from the authors upon request.

\section{Statistical analysis}

Statistical analysis was calculated using SPSS16.0 software. Genotype and allele frequencies were computed by counting. Hardy-Weinberg equilibrium was tested using the chi-square test. Disparity of the characteristics between AD patients and control subjects were tested by the Student- $t$ test or the $\chi 2$ test. The distributions of genotypes and alleles between the two groups were compared using the $\chi 2$ test. Differences between the two groups after stratification for $A P O E \& 4$ status were also examined by the $\chi 2$ test. For further analysis of the frequencies of the AD patients and control subjects, we defined various genetic models as $1(\mathrm{CC}+\mathrm{CT})$ versus 0 (TT) for dominant, 1 (CC) versus $0(\mathrm{CT}+\mathrm{TT})$ for recessive, and 2 (CC) versus 1 (CT) versus 0 (TT) for additive. We then tested them using logistic regression adjusted for age, gender, and $A P O E \& 4$ status (presence or absence of $\varepsilon 4$ allele). The significance of an SNP $\times A P O E$ $\varepsilon 4$ interaction was also tested for this SNP by logistic regression. The $P$ value, odds ratios (ORs) and 95\% confidence intervals (CIs) were computed. The criterion for significant difference is $P<0.05$. A Bonferronicorrected $P(P c)$ value was computed to control false discovery rate. Estimation of the statistical power was performed with STPLAN 4.3 software.

Furthermore, we combined our data with the results from meta-analysis of 74,046 individuals [11] and other reports about $Z C W P W 1$ (rs1476679) and LOAD [16-18] by fixed-effects inverse variance-weighted methods. Meanwhile, we generated $\mathrm{I}^{2}$ estimates with evaluate the possible effect of study heterogeneity on the results. We used Stata V.12.0 to perform all themeta-analyses. 


\section{ACKNOWLEDGMENTS AND FUNDING}

This work was supported by grants from the National Natural Science Foundation of China (81471309, $81371406,81571245,81501103)$, the Shandong Provincial Outstanding Medical Academic Professional Program, Qingdao Key Health Discipline Development Fund, Qingdao Outstanding Health Professional Development Fund, and Shandong Provincial Collaborative Innovation Center for Neurodegenerative Disorders.

\section{CONFLICTS OF INTEREST}

The authors disclose no conflicts of interest.

\section{REFERENCES}

1. Tan MS, Yu JT, Jiang T, Zhu XC, Wang HF, Zhang W, Wang YL, Jiang W, Tan L. NLRP3 polymorphisms are associated with late-onset Alzheimer's disease in Han Chinese. J Neuroimmunol. 2013; 265:91-95.

2. Tan L, Yu JT, Zhang W, Wu ZC, Zhang Q, Liu QY, Wang W, Wang HF, Ma XY, Cui WZ. Association of GWAS-linked loci with late-onset Alzheimer's disease in a northern Han Chinese population. Alzheimers Dement. 2013; 9:546-553.

3. Wang J, Yu JT, Jiang T, Tan MS, Wang HF, Tan L, Hu N, Sun L, Zhang W, Tan L. Association of LRRTM3 polymorphisms with late-onset Alzheimer's disease in Han Chinese. Exp Gerontol. 2014; 52:18-22.

4. Carrasquillo MM, Belbin O, Hunter TA, Ma L, Bisceglio GD, Zou F, Crook JE, Pankratz VS, Dickson DW, Graff-Radford NR, Petersen RC, Morgan K, Younkin SG. Replication of CLU, CR1, and PICALM associations with alzheimer disease. Arch Neurol. 2010; 67:961-964

5. Guerreiro R, Wojtas A, Bras J, Carrasquillo M, Rogaeva E, Majounie E, Cruchaga C, Sassi C, Kauwe JS, Younkin S, Hazrati L, Collinge J, Pocock J, et al. TREM2 variants in Alzheimer's disease. N Engl J Med. 2013; 368:117-127.

6. Hollingworth P, Harold D, Sims R, Gerrish A, Lambert JC, Carrasquillo MM, Abraham R, Hamshere ML, Pahwa JS, Moskvina V, Dowzell K, Jones N, Stretton A, et al. Common variants at ABCA7, MS4A6A/MS4A4E, EPHA1, CD33 and CD2AP are associated with Alzheimer's disease. Nat Genet. 2011; 43:429-435.

7. Harold D, Abraham R, Hollingworth P, Sims R, Gerrish A, Hamshere ML, Pahwa JS, Moskvina V, Dowzell K, Williams A, Jones N, Thomas C, Stretton A, et al. Genomewide association study identifies variants at CLU and PICALM associated with Alzheimer's disease. Nat Genet. 2009; 41:1088-1093.

8. Lambert JC, Heath S, Even G, Campion D, Sleegers K, Hiltunen M, Combarros O, Zelenika D, Bullido MJ, Tavernier B, Letenneur L, Bettens K, Berr C, et al. Genomewide association study identifies variants at CLU and CR1 associated with Alzheimer's disease. Nat Genet. 2009; 41:1094-1099.

9. Naj AC, Jun G, Beecham GW, Wang LS, Vardarajan BN, Buros J, Gallins PJ, Buxbaum JD, Jarvik GP, Crane PK, Larson EB, Bird TD, Boeve BF, et al. Common variants at MS4A4/MS4A6E, CD2AP, CD33 and EPHA1 are associated with late-onset Alzheimer's disease. Nat Genet. 2011; 43:436-441.

10. Seshadri S, Fitzpatrick AL, Ikram MA, DeStefano AL, Gudnason V, Boada M, Bis JC, Smith AV, Carassquillo MM, Lambert JC, Harold D, Schrijvers EM, Ramirez-Lorca R, et al. Genome-wide analysis of genetic loci associated with Alzheimer disease. JAMA. 2010; 303:1832-1840.

11. Lambert JC, Ibrahim-Verbaas CA, Harold D, Naj AC, Sims R, Bellenguez C, DeStafano AL, Bis JC, Beecham GW, Grenier-Boley B, Russo G, Thorton-Wells TA, Jones N, et al. Meta-analysis of 74,046 individuals identifies 11 new susceptibility loci for Alzheimer's disease. Nat Genet. 2013; 45:1452-1458.

12. He F, Umehara T, Saito K, Harada T, Watanabe S, Yabuki T, Kigawa T, Takahashi M, Kuwasako K, Tsuda K, Matsuda T, Aoki M, Seki E, et al. Structural insight into the zinc finger $\mathrm{CW}$ domain as a histone modification reader. Structure. 2010; 18:1127-1139.

13. Rosenthal SL, Barmada MM, Wang X, Demirci FY, Kamboh MI. Connecting the dots: potential of data integration to identify regulatory SNPs in late-onset Alzheimer's disease GWAS findings. PLoS One. 2014; 9:e95152.

14. Yokoyama K, Tezuka T, Kotani M, Nakazawa T, Hoshina N, Shimoda Y, Kakuta S, Sudo K, Watanabe K, Iwakura Y, Yamamoto T. NYAP: a phosphoprotein family that links PI3K to WAVE1 signalling in neurons. EMBO J. 2011; 30:4739-4754.

15. Escott-Price V, Bellenguez C, Wang LS, Choi SH, Harold D, Jones L, Holmans P, Gerrish A, Vedernikov A, Richards A, DeStefano AL, Lambert JC, Ibrahim-Verbaas CA, et al. Gene-Wide Analysis Detects Two New Susceptibility Genes for Alzheimer's Disease. PLoS One. 2014; 9.

16. Ruiz A, Heilmann S, Becker T, Hernandez I, Wagner H, Thelen M, Mauleon A, Rosende-Roca M, Bellenguez C, Bis JC, Harold D, Gerrish A, Sims R, et al. Follow-up of loci from the International Genomics of Alzheimer's Disease Project identifies TRIP4 as a novel susceptibility gene. Transl Psychiatry. 2014; 4:e358.

17. Xiao Q, Liu ZJ, Tao S, Sun YM, Jiang D, Li HL, Chen H, Liu X, Lapin B, Wang CH, Zheng SL, Xu J, Wu ZY. Risk prediction for sporadic Alzheimer's disease using genetic risk score in the Han Chinese population. Oncotarget. 2015; 6:36955-36964. doi: 10.18632/oncotarget.6271.

18. Jiao B, Liu X, Zhou L, Wang MH, Zhou Y, Xiao T, Zhang W, Sun R, Waye MM, Tang B, Shen L. Polygenic Analysis of Late-Onset Alzheimer's Disease from Mainland China. PLoS one. 2015; 10:e0144898.

19. Wang X, Lopez OL, Sweet RA, Becker JT, DeKosky ST, Barmada MM, Demirci FY, Kamboh MI. Genetic 
determinants of disease progression in Alzheimer's disease. J Alzheimers Dis. 2015; 43:649-655.

20. Liu QY, Miao D, Yu JT, Xing YY, Zhong XL, Wu ZC, Zhang Q, Tan L. Lack of association between rs597668 polymorphism near EXOC3L2 and late-onset Alzheimer's disease in Han Chinese. Neurosci Lett. 2012; 513:174-177.

21. Rosenthal SL, Kamboh MI. Late-Onset Alzheimer's Disease Genes and the Potentially Implicated Pathways. Curr Genet Med Rep. 2014; 2:85-101.

22. Medway C, Morgan K. Review: The genetics of Alzheimer's disease; putting flesh on the bones. Neuropathol Appl Neurobiol. 2014; 40:97-105.

23. Beecham GW, Hamilton $\mathrm{K}$, Naj AC, Martin ER, Huentelman M, Myers AJ, Corneveaux JJ, Hardy J, Vonsattel JP, Younkin SG, Bennett DA, De Jager PL, Larson EB, et al. Genome-wide association meta-analysis of neuropathologic features of Alzheimer's disease and related dementias. PLoS Genet. 2014; 10:e1004606.
24. McKhann G, Drachman D, Folstein M, Katzman R, Price D, Stadlan EM. Clinical diagnosis of Alzheimer's disease: report of the NINCDS-ADRDA Work Group under the auspices of Department of Health and Human Services Task Force on Alzheimer's Disease. Neurology. 1984; 34:939-944.

25. Yu JT, Miao D, Cui WZ, Ou JR, Tian Y, Wu ZC, Zhang W, Tan L. Common variants in toll-like receptor 4 confer susceptibility to Alzheimer's disease in a Han Chinese population. Curr Alzheimer Res. 2012; 9:458-466. 